\title{
Self-perceived Risk of Breast Cancer and Screening Behaviors of First-degree Female Relatives of Breast Cancer Patients at the Uganda Cancer Institute, Uganda
}

\section{Provia Ainembabazi ( $\sim$ aineprovia@gmail.com )}

Department of Nursing, School of Health Sciences, College of Health Sciences, Makerere University Derrick Bary Abila

Department of Pathology, School of Biomedical Sciences, College of Health Sciences, Makerere University

\section{Grace Manyangwa}

Uganda Cancer Institute, Upper Mulago Hill Road

\section{Godwin Anguzu}

Infectious Diseases Institute, College of Health Sciences, Makerere University

Innocent Mutyaba

Uganda Cancer Institute, Upper Mulago Hill Road

Charles Peter Osingada

Department of Nursing, School of Health Sciences, College of Health Sciences, Makerere University Amos Deogratius Mwaka

Department of Medicine, School of Medicine, College of Health Sciences, Makerere University

\section{Research Article}

Keywords: Breast cancer, risk perception, self-perceived risk, screening behaviors, first-degree relatives

Posted Date: March 26th, 2021

DOl: https://doi.org/10.21203/rs.3.rs-343329/v1

License: (c) (1) This work is licensed under a Creative Commons Attribution 4.0 International License. Read Full License 


\section{Abstract}

\section{Introduction}

In Uganda, Breast cancer is the most common cancer in females globally. The majority of the patients present with advanced-stage disease at diagnoses and experience high mortality. This underscores the importance of early detection approaches based on awareness of risk factors and self-perceived risks, and symptoms of the disease to promote adoption of risk reduction behaviors and prompt health-seeking respectively. This study assessed the self-perceived risk of breast cancer, and breast cancer screening behaviours among first-degree female relatives of breast cancer patients in Uganda.

\section{Methods}

This was a cross-sectional study employing quantitative approaches for data collection and analyses. First-degree female relatives of patients attending care at Uganda Cancer Institute were recruited consecutively in the study. A pre-tested coded questionnaire was used to collect data on self-perceived risks, breast cancer risks, and breast cancer screening behaviours. Data were collected between March to October 2019. A modified Poisson regression model was used to evaluate factors associated with selfperceived risk of breast cancer and breast cancer risk awareness.

\section{Results}

We enrolled 296 first-degree female relatives from 197 female breast cancer patients. The median age (IQR) was $33(26-43)$ years. A majority $(60.1 \%, 178 / 296)$ of the participants had a low self-perceived risk of breast cancer. Breast self-examination $(55.7 \%, 165 / 296)$ was the most practiced screening method followed by clinical breast examination $(n=64 / 296,21.6 \%)$, ultrasound scan of the breast $(7.8 \%$, $23 / 296$ ), and mammogram $(3.7 \%, 11 / 296)$. Women aged $35-44$ years had a higher self-perceived risk of breast cancer (adjusted Incident Rate Ratio [aIRR]: 1.75, 95\% Cl: 1.10-2.80), compared to women aged 1825 years.

\section{Conclusion}

First-degree relatives reported a low self-perceived risk of breast cancer. Breast cancer health education especially targeting younger women should emphasize the increased risk of breast cancer in first-degree relatives of patients with breast cancer. There is a need to increase awareness of breast cancer screening methods and their usefulness in the early detection of breast cancer among all women in Uganda.

\section{Introduction}

Breast cancer is the most common malignancy among women in developing and developed countries(1). In 2018 and 2020, it was estimated that 2.1 million and 2.3 million new breast cancer cases were diagnosed constituting $11.6 \%$ and $11.7 \%$ of all incident cancer cases worldwide respectively $(1-3)$. In Uganda, 2,639 new cases of breast cancer were recorded in 2020, accounting for $7.8 \%$ of all new cancer 
cases in both sexes. Among females, breast cancer incidence (13.5\% of all female cancers) was only second to cervical cancer and accounted for $5.9 \%$ of all deaths from cancers(1). While there is a high incidence of breast cancer in high-income countries, the disease causes more mortality in Low-and Middle-Income Countries (4-6). The predominantly advanced-stage cancer at diagnoses and high mortality rate in the less developed countries has been attributed to the lack of adequate facilities for diagnosis and treatment and early detection programs (7-9). This is in contrast to developed countries where survival rates are high and screening programs available particularly for populations that are at higher risk of breast cancer (10). Screening for breast cancer has been associated with a reduction in mortality from the disease (11). This underscores the importance of ensuring the availability of screening services particularly for populations that are at high risk. Uptake of screening services and adoption of risk reduction strategies, in general, depends on several factors including awareness, availability of the services, and self-perceived risk to the disease/cancer.

First-degree relatives (FDRs) of breast cancer patients experience an elevated risk of breast cancer compared to the general population (12). Females who are related to at least one breast cancer patient are more than two times likely to develop breast cancer compared to those without a family history of breast cancer. The risks of developing breast cancer are even higher when they are related to more than one patient (13-15). Because FDRs are at increased susceptibility to breast cancer, several studies have explored how FDRs understand their risk of breast cancer and how this informs their adoption of risk reduction and health-seeking behaviors (16-18). Understanding the self-perceived risks and awareness of breast cancer risk factors and symptoms of FDRs of breast cancer patients potentially guides policymakers and healthcare professionals on the design of targeted interventions to promote risk reduction and prompt health-seeking for symptoms of breast cancer among the FDRs of breast cancer patients. However, there are limited data on self-perceived risk for breast cancer and screening behaviors of the FDRs of breast cancer patients in Uganda. Therefore, the purpose of this study was to assess the self-perceived and screening behaviors of FDRs of breast cancer patients attending care at the Cancer Institute in Uganda to inform interventions to promote risk factor awareness, an appropriate understanding of self-risks, adoption of risk reduction behaviors, and prompt health-seeking for symptoms suggestive of breast cancer.

\section{Methods}

\section{Study design and site}

This was a cross-sectional study conducted at the breast cancer clinic and in-patient wards of the Uganda Cancer Institute (UCl). The Uganda Cancer Institute is a tertiary cancer care facility located in Kampala, Uganda. The Institute is the main specialized cancer center for training, research, and patient care in the country(19).

\section{Study Population}


We enrolled female FDRs of female breast cancer patients (daughter, sister, or mother to a female breast cancer patient) receiving care at the $\mathrm{UCl}$. Participants were included in the study if they were aged 18 years and older, had no personal history of breast cancer, willing to provide written informed consent to participate in the study, and able to express themselves in English or Luganda (the predominant language in Kampala).

\section{Participant recruitment and data collection}

Consecutive sampling was used to enroll female first-degree relatives of breast cancer patients. The breast cancer patients were approached as they waited for treatment from the out-patients clinic. Also, stable patients who were admitted in the wards were approached and requested to identify FDRs who could be included in the study. If the patient had three or fewer first-degree female relatives, all of them were included in the study. In cases where the patient had more than three first-degree female relatives, the first three who were able to travel to the UCI for the interview were considered. The FDRs were individually contacted and requested to travel to the UCI for an interview. Those who managed to travel were given information about the objectives of the study and provided with the opportunity to ask questions. Informed consent was then sought from those who agreed to participate in the study. Interviews were conducted in a quiet room with sufficient privacy. Trained research assistants collected data under the supervision of the investigators. The research assistants followed written Standard Operating Procedures (SOPs) for recruitment, consenting, and data collection. Each interview lasted about 30 minutes. All study procedures were performed in accordance with Good Clinical Practice, National and International guidelines and regulations for the conduct of research.

\section{Measurements}

Data were collected using an interviewer-administered questionnaire either in English or Luganda. The first part of the questionnaire assessed participants' socio-demographic characteristics e.g. age, marital status, education attainment, religion, and region of residence in Uganda. The second part assessed breast cancer self-perceived risk using a verbal measure that has been used in previous studies (20). The verbal measure explores participant's response to the question; 'My chances of getting breast cancer are great' on a Likert scale with 5 response alternatives (strongly disagree (1), disagree (2), neutral (3), agree (4), and strongly disagree (5). At analysis, a participant was categorized to have low self-perceived risk if she selected strongly disagree or disagree, and high self-perceived risk if she selected neutral, agree, or strongly agree as a response to the above question. The third part assessed breast cancer risk reduction behaviours i.e. self-breast examination, clinical breast examination, ultrasound scan, and mammography. The questionnaire was pre-tested with the relatives of breast cancer patients at Uganda Cancer Institute. The women included in the pre-test did not participate in the main study.

\section{Data management and analysis}


Data was done using Epidata version 3.1 software. The final data was backed up before exporting a copy to STATA version 14.1 for analysis. We described the study population using proportions for categorical variables; medians and interquartile range for continuous variables. At bivariable analysis, we examined the associations between socio-demographic characteristics, breast cancer screening, and breast cancer self-perceived risk using chi-square tests and rank-sum tests respectively. We used a modified Poisson regression model to evaluate factors associated with the self-perceived risk of breast cancer among the participants $(21,22)$. Poisson regression models with robust variances were used to estimate incidence rate ratios at $95 \%$ confidence intervals. Rate ratios closely approximate risk ratios when the outcome is common $(21,23)$.

\section{Results}

\section{Social demographic characteristics of first-degree female relatives}

We enrolled 296 first-degree relatives of 197 female breast cancer patients. The median age (IQR) of the participants was $33(26-43)$ years. Most of the participants were aged between $26-35$ years $(36.1 \%$, $107 / 296)$. The majority of the participants were married $(50.3 \%, 149 / 296)$, attained at least secondary education $(33.1 \%, 98 / 296)$, and were from the central region $(58.8 \%, 174 / 296)$ (Table 1$)$. 
Table 1

Social demographic characteristics of first-degree female relatives

\begin{tabular}{|c|c|c|}
\hline Socio-demographic factors & Frequency & Percentage \\
\hline Age; median (IQR) & $33(26-43)$ & \\
\hline $18-25$ & 68 & 23.0 \\
\hline $26-35$ & 107 & 36.1 \\
\hline $36-45$ & 63 & 21.3 \\
\hline$\geq 46$ & 58 & 19.6 \\
\hline \multicolumn{3}{|l|}{ Marital status } \\
\hline Married & 149 & 50.3 \\
\hline Single & 113 & 38.2 \\
\hline Divorced & 21 & 7.1 \\
\hline Widow & 13 & 4.4 \\
\hline \multicolumn{3}{|l|}{ Religion } \\
\hline Catholic & 104 & 35.1 \\
\hline Anglican & 77 & 26.0 \\
\hline Moslem & 58 & 19.6 \\
\hline Born again & 47 & 15.9 \\
\hline Other & 10 & 3.4 \\
\hline \multicolumn{3}{|l|}{ Education level } \\
\hline None & 9 & 3.0 \\
\hline Primary & 71 & 24.0 \\
\hline Secondary & 98 & 33.1 \\
\hline Tertiary & 58 & 19.7 \\
\hline University & 59 & 19.9 \\
\hline Missing & 01 & 0.3 \\
\hline \multicolumn{3}{|l|}{ Residence } \\
\hline Rural & 112 & 37.8 \\
\hline Urban & 183 & 61.8 \\
\hline
\end{tabular}




\begin{tabular}{|lll|}
\hline Socio-demographic factors & Frequency & Percentage \\
\hline Missing & 01 & 0.4 \\
\hline Origin & & \\
Central & 174 & 58.8 \\
Western & 33 & 11.2 \\
\hline Eastern & 55 & $18.5)$ \\
\hline Northern & 34 & 11.5 \\
\hline
\end{tabular}

\section{Self-perceived of breast cancer and associated factors}

A majority $(60.1 \%, 178 / 296)$ of the participants perceived themselves to be at low risk of developing breast cancer. Age was the only factor significantly associated with a high self-perceived risk of developing breast cancer among the first-degree female relatives of the breast cancer patients. After controlling for education level, area of residence, and religion, women aged 35-44 years had a higher self-perceived risk of breast cancer (adjusted Incident Rate Ratio [aIRR]: 1.75, 95\%, Cl: 1.10-2.80) compared to women aged $18-25$ years (Table 2 ). 
Table 2

Socio-demographic factors and self-perceived risk of breast cancer

$\begin{array}{lllll}\text { Characteristics } & \begin{array}{l}\text { Unadjusted Incident Risk } \\ \text { ratios } \\ (95 \% \mathrm{Cl})\end{array} & \begin{array}{l}\text { P- } \\ \text { value }\end{array} & \begin{array}{l}\text { Adjusted Incident Risk } \\ \text { Ratio } \\ (95 \% \mathrm{Cl})\end{array} & \begin{array}{l}\text { P- } \\ \text { value }\end{array} \\ & & & (950)\end{array}$

\section{Socio-demographic factors}

Age group

$18-25$

1.00

1.00

$26-35$

$1.47(0.94-2.30)$

0.09

$1.50(0.96-2.36)$

0.08

$36-45$

$1.76(1.11-2.78)$

0.02

$1.75(1.10-2.80)$

0.02

$>=46$

$1.48(0.91-2.42)$

$0.12 \quad 1.45(0.88-2.40)$

0.15

Marital status

Married $\quad 1.00$

Single

$1.01(0.77-1.34)$

0.93

Religion

Christian

1.00

1.00

Moslem

$1.34(0.98-1.82)$

0.06

$1.30(0.96-1.77)$

0.09

\section{Education level}

Primary
Secondary
$\begin{aligned} & \text { Tertiary/ } \\ & \text { University }\end{aligned}$
Residence

Urban

1

$\begin{array}{lll}\text { Rural } & 1.22(0.92-1.62) & 0.93\end{array}$

\section{Region}

Central 1

Western

$0.90(0.56-1.47)$

0.68

Eastern

$0.99(0.69-1.44)$

0.98

Northern

$1.02(0.66-1.59)$

0.92 


\section{Breast cancer screening practices}

One hundred and sixty-five $(55.7 \%, 165 / 296)$ participants self-reporting ever performing Breast SelfExamination (BSE); 66\% (109/165) of them had last examined their breasts within a month of this study interview. The median age (Interquartile range, IQR) at which first-degree relatives began performing BSE was 28 (22-37) years. Only 21.6\% (64/296) of the first-degree relatives had ever visited a healthcare professional for a Clinical Breast Examination (CBE). Of those who underwent CBE, 42.2\% (27/ 64) visited a healthcare professional for CBE because they wanted to know their breast cancer status. Only $7.8 \%$ $(23 / 296)$ of all first-degree relatives had ever had an ultrasound scan of the breast. The most cited reason for performing an ultrasound scan of the breast was self-noticed changes in the breast $(60.9 \%, 14 / 23)$ (Table 3). 
Table 3

Breast cancer screening practices

\begin{tabular}{|c|c|c|}
\hline Self-breast examination & Frequency & percentages \\
\hline \multicolumn{3}{|l|}{ Performs breast self-examination } \\
\hline Yes & 165 & 55.7 \\
\hline No & 131 & 44.3 \\
\hline \multicolumn{3}{|l|}{ Perform breast self-examination every ( $\mathrm{N}=165)$} \\
\hline Every 6 months & 21 & 12.7 \\
\hline Once a month & 73 & 44.3 \\
\hline Once a week & 33 & 20.0 \\
\hline Others & 38 & 23.0 \\
\hline \multicolumn{3}{|l|}{ Last performed the breast self-examination $(\mathrm{N}=165)$} \\
\hline Less than a month ago & 109 & 66.1 \\
\hline $2-6$ months ago & 29 & 17.6 \\
\hline 6 months -1 year ago & 21 & 12.7 \\
\hline More than 1 year ago & 3 & 1.8 \\
\hline Missing & 3 & 1.8 \\
\hline Age of first breast self- examination; median (IQR), $(\mathrm{N}=165)$ & $28(22-37)$ & \\
\hline \multicolumn{3}{|l|}{ Clinical breast examination: } \\
\hline \multicolumn{3}{|l|}{ Ever visited a doctor for a clinical breast examination } \\
\hline Yes & 64 & 21.6 \\
\hline No & 232 & 78.4 \\
\hline \multicolumn{3}{|l|}{ Last visited a doctor for a clinical breast exam $(\mathrm{N}=64)$} \\
\hline Less than a month ago & 9 & 14.1 \\
\hline $2-6$ months ago & 15 & 23.4 \\
\hline $6-1$ year ago & 13 & 20.3 \\
\hline More than 1 year ago & 27 & 42.2 \\
\hline \multicolumn{3}{|l|}{ Indication for Clinical Breast Examination ( $\mathrm{N}=64)$} \\
\hline Noticed a change in my breast & 18 & 28.1 \\
\hline Wanted to know their breast cancer status & 27 & 42.2 \\
\hline
\end{tabular}




\begin{tabular}{|c|c|c|}
\hline Self-breast examination & Frequency & percentages \\
\hline Medical advice/procedure & 18 & 28.1 \\
\hline Missing & 1 & 1.6 \\
\hline \multicolumn{3}{|l|}{ Ultrasound scan } \\
\hline \multicolumn{3}{|l|}{ Ever done an ultrasound scan of the breast } \\
\hline Yes & 23 & 7.8 \\
\hline No & 273 & 92.2 \\
\hline \multicolumn{3}{|c|}{ Last performed an ultrasound scan of the breast $(\mathrm{N}=23)$} \\
\hline Less than a month ago & 1 & 4.4 \\
\hline $2-6$ months ago & 3 & 13.0 \\
\hline 6 months -1 years ago & 7 & 30.4 \\
\hline More than 1 year ago & 12 & 52.2 \\
\hline \multicolumn{3}{|c|}{ Indication for the ultrasound scan of the breast $(\mathrm{N}=23)$} \\
\hline Noticed a change in the breast & 14 & 60.9 \\
\hline Wanted to know their breast cancer status & 6 & 26.1 \\
\hline Medical advice/procedure & 3 & 13.0 \\
\hline \multicolumn{3}{|l|}{ Mammography } \\
\hline \multicolumn{3}{|l|}{ Ever done mammography } \\
\hline Yes & 11 & 3.7 \\
\hline No & 285 & 96.3 \\
\hline \multicolumn{3}{|l|}{ Mammography last done $(\mathrm{N}=11)$} \\
\hline $2-6$ months ago & 2 & 18.2 \\
\hline 6 months -1 year ago & 3 & 27.3 \\
\hline More than 1 year ago & 6 & 54.5 \\
\hline \multicolumn{3}{|l|}{ Indication for Mammography } \\
\hline Noticed a change in the breast & 5 & 45.5 \\
\hline Wanted to know their breast cancer status & 4 & 36.4 \\
\hline Medical advice/Procedure & 2 & 18.2 \\
\hline
\end{tabular}




\section{Breast cancer self-perceived risk and breast cancer screening behaviors}

We did not find significant associations between age, marital status, education, and other sociodemographic factors of the participants with the self-perceived risk of breast cancer (Table 4).

Table 4

Associations between self-perceived risk and risk reduction behaviors

\begin{tabular}{|llll|}
\hline Variable & $\begin{array}{l}\text { Low Risk } \\
\mathbf{n}(\%)\end{array}$ & $\begin{array}{l}\text { High risk } \\
\mathbf{n}(\%)\end{array}$ & P-Value \\
\hline Breast Self-Examination & & & 0.31 \\
\hline Yes & $95(53.4)$ & $70(59.3)$ & \\
\hline No & $83(46.6)$ & $48(40.7)$ & \\
\hline Clinical Breast Examination & & & 0.66 \\
\hline Yes & $40(22.5)$ & $24(20.3)$ & \\
\hline No & $138(77.5)$ & $94(79.7)$ & \\
\hline Ultrasound Scan of the breast & & & \\
\hline Yes & $15(8.4)$ & $8(6.8)$ & \\
\hline No & $163(91.6)$ & $110(93.2)$ & \\
\hline Mammography & & & \\
\hline Yes & $7(3.9)$ & $4(3.4)$ & \\
\hline No & $171(96.1)$ & $114(96.6)$ & \\
\hline
\end{tabular}

\section{Discussion}

We found that less than half of the participants perceived themselves to be at a high risk of developing breast cancer especially because they had a relative with breast cancer. Older women were more likely to perceive themselves to be at higher risk of developing breast cancer, mainly because they had a relative with breast cancer. We found a low uptake of breast cancer screening services among this study population. Mammography was the least undertaken of the risk reduction and screening behaviors (others self-breast examinations, clinical breast examinations and breast ultra sound scans) assessed in this study.

Risk perception is critical in determining an individual's appraisal of susceptibility to disease and influences the likelihood of taking a preventive action (24). In this study, less than half of the participants 
perceived themselves to be at risk of breast cancer. This finding is lower than the fifty-five percent reported by Royak-Schaller et al (1995) but close to results from a recent quantitative study by Seven et al (2018) where almost half of the participants moderately worried about the chance of getting breast cancer and another fifty percent ranked their risk as moderate $(18,25)$. In a qualitative study by Spector et al (2009), women perceived themselves to be at a heightened risk of breast cancer and nearly one-fifth of the respondents considered themselves below average risk (26). Understanding cancer self-perceived risk can be challenging and it is not unusual to find discrepancies between perceived and objective breast cancer risk. This may arise from the way participants understand the concept of risk (27). It may also be due to misleading information from the media and inadequately informed healthcare professionals.

We also found that breast cancer self-perceived risk was significantly associated with the age of the participant. The strength of the association between age and risk perception increased for participants aged twenty-six years to forty-five years and thereafter it declined. This is not easily comparable with studies from other settings that enrolled older populations greater than thirty years. These studies reported that higher perceived risk is correlated with younger (28-30). However, it is important to note that in most developing countries cancer of the breast tends to occur in younger women below the age of 50 years unlike the case in most developed countries where the incidence of breast cancer is higher in women aged beyond 50 years (31). Younger women in the low- and middle-income countries need to be aware that they are at risk of developing breast cancer and therefore encouraged to undertake appropriate risk-reduction and early detection measures.

In this study, the most practiced preventive behavior was a self-breast examination and the least utilized modality was mammography. Low uptake of mammography may be a result of several factors including lack of access to the services, high costs, and low knowledge about the service (32). For some developed countries, it is recommended that individuals at an elevated risk for breast cancer start mammographic screening earlier and have supplemental screening modalities (10). However, in most resources limited setting such services are simply not available and the cost of providing them is extremely prohibitive especially in the context of other competing demands. Thus, it is not surprising that an exceedingly small proportion of the participants had ever had a mammogram done. Although the benefit of proving largescale mammography screening in less developed countries is open to debate (33), perhaps modalities should be developed for providing such services to the most at-risk populations such as FDRs.

\section{Limitations}

Our study had some limitations. First, we were not able to achieve our computed sample size because of the difficulties we encountered in recruiting participants. For example, first-degree relatives staying beyond the $40 \mathrm{Km}$ radius from the study site were unable to travel to the study site to participate in the study. The study team made efforts to amend the protocol to have these enrolled in the study through telephone interviews, which was declined given the risk of the study. However, we believe that with the sample used, the study was powered enough to allow us to detect differences between the groups. Second, this was a cross-sectional study; we could not dissect to establish at what point the self- 
perceived risk changed even though we restricted the participants to compare since when the index patient was diagnosed. Participants could have simply stated their current perceptions which are influenced more by the sight of the multitude of breast cancer patients rather than just their relatives.

\section{Conclusion}

The majority of the participants perceived themselves to have a low likelihood of developing breast cancer in their lifetime and did not practice risk reduction measures even though they had biological relatives with breast cancer. The older women were more likely to perceive themselves to be at higher risk of developing breast cancer compared to the younger women. Breast cancer health education with an emphasis on risk factors including being a first-degree female relative to a breast cancer patient is a necessary though not sufficient intervention to improve uptake of risk reduction measures and reduce the incidence of breast cancer.

\section{Abbreviations}

BSE Breast Self- Examination

CBE Clinical Breast Examination

FDRs First Degree Relatives

GLOBOCAN Global Cancer

\section{Declarations}

\section{Ethics approval and consent to participate:}

The study was approved by the Uganda Cancer Institute Research Ethics Committee (\#UCIREC-REF-192017) and Uganda National Council of Science and Technology (HS277ES). Informed consent was sought from all participants after a clear explanation was provided about the objectives of the study, risk factors, and the benefits. Confidentiality and privacy were observed during the conduct of the interviews. The identification numbers were used to identify participants instead of their names. All study procedures were performed in accordance with Good Clinical Practice, National and International guidelines and regulations for the conduct of research.

\section{Consent for publication:}

Not applicable. The manuscript does not contain any personally identifiable data.

\section{Availability of data and materials:}


The datasets used and/or analyzed during the current study are available from the corresponding author on a reasonable request.

\section{Competing interests:}

Authors declare that there are no competing interests.

\section{Funding:}

The study is supported by the African Development Bank and Uganda Cancer Institute under the Young Investigators' Award. The funding bodies did not have a role in the design of the study and collection, analysis, and interpretation of data and in writing the manuscript.

\section{Authors' contributions}

PA, DBA, CPO, and ADM conceptualized the study, participated in writing the protocol, interpreted the results, and reviewed the manuscript.

PA and DBA acquired regulatory approvals, supervised data collection, and drafted the manuscript.

$\mathrm{GA}, \mathrm{AP}$, and $\mathrm{ADB}$ conducted data analysis and interpreted results.

GM and IM participated in the supervision of data collection and reviewed the final manuscript.

All authors read and agreed on the final manuscript.

\section{Acknowledgments:}

We would like to thank the breast cancer patients and their relatives who participated in the study. We would like to extend our sincere gratitude to Ms. Freida Wabwire for directing/recruiting the participants from the breast cancer clinic to the study room and Ms. Olivia Sentanda for data collection.

\section{References}

1. Sung H, Ferlay J, Siegel RL, Laversanne M, Soerjomataram I, Jemal A, et al. Global cancer statistics 2020: GLOBOCAN estimates of incidence and mortality worldwide for 36 cancers in 185 countries. CA: a cancer journal for clinicians. 2021.

2. Bray F, Ferlay J, Soerjomataram I, Siegel RL, Torre LA, Jemal A. Global cancer statistics 2018 : GLOBOCAN estimates of incidence and mortality worldwide for 36 cancers in 185 countries. CA: a cancer journal for clinicians. 2018;68(6):394-424. 
3. International agency for research on cancer [Internet]. 2019. Available from: http://gco.iarc.fr/today\%0Ahttps://gco.iarc.fr/today/data/factsheets/populations/900-world-factsheets.pdf.

4. Ahamad A. Breast cancer statistics: Recent trends. In Breast Cancer metastasis and drug resistance, advances in experimental medicine and Biology2019.

5. Rivera-Franco MM, Leon-Rodriguez E. Delays in Breast Cancer Detection and Treatment in Developing Countries. Breast cancer : basic and clinical research. 2018;12:1178223417752677.

6. Torre LA, Bray F, Siegel RL, Ferlay J, Lortet-Tieulent J, Jemal A. Global cancer statistics, 2012. CA: a cancer journal for clinicians. 2015;65(2):87-108.

7. Fregene A, Newman LA. Breast cancer in sub-Saharan Africa: how does it relate to breast cancer in African-American women? Cancer. 2005;103(8):1540-50.

8. Basro S, Apffelstaedt JP. Breast cancer in young women in a limited-resource environment. World journal of surgery. 2010;34(7):1427-33.

9. da Costa Vieira RA, Biller G, Uemura G, Ruiz CA, Curado MP. Breast cancer screening in developing countries. Clinics (Sao Paulo, Brazil). 2017;72(4):244-53.

10. Monticciolo DL, Newell MS, Moy L, Niell B, Monsees B, Sickles EA. Breast Cancer Screening in Women at Higher-Than-Average Risk: Recommendations From the ACR. Journal of the American College of Radiology : JACR. 2018;15(3 Pt A):408-14.

11. Kalager $M$, Zelen $M$, Langmark $F$, Adami HO. Effect of screening mammography on breast-cancer mortality in Norway. The New England journal of medicine. 2010;363(13):1203-10.

12. Nelson HD, Zakher B, Cantor A, Fu R, Griffin J, O'Meara ES, et al. Risk factors for breast cancer for women aged 40 to 49 years: a systematic review and meta-analysis. Ann Intern Med. 2012;156(9):635.

13. Pharoah PD, Day NE, Duffy S, Easton DF, Ponder BA. Family history and the risk of breast cancer: a systematic review and meta-analysis. International journal of cancer. 1997;71(5):800-9.

14. Review: breast cancer is associated with a family history of the disease in first degree relatives. Evidence Based Nursing. 2002;5(3):89.

15. Singletary SE. Rating the risk factors for breast cancer. Ann Surg. 2003;237(4):474-82.

16. Royak-Schaler R, deVellis BM, Sorenson JR, Wilson KR, Lannin DR, Emerson JA. Breast cancer in African-American families. Risk perception, cancer worry, and screening practices of first-degree relatives. Annals of the New York Academy of Sciences. 1995;768(1):281-5.

17. Sheinfeld Gorin S, Albert SM. The meaning of risk to first degree relatives of women with breast cancer. Women Health. 2003;37(3):97-117.

18. Seven M, Bağcivan G, Akyuz A, Bölükbaş F. Women with Family History of Breast Cancer: How Much Are They Aware of Their Risk? J Cancer Educ. 2018;33(4):915-21.

19. Savage L. Former African cancer research powerhouse makes plans for a return to greatness. Journal of the National Cancer Institute. 2007;99(15):1144-5, 51. 
20. Kartal M, Ozcakar N, Hatipoglu S, Tan MN, Guldal AD. Breast cancer risk perceptions of Turkish women attending primary care: a cross-sectional study. BMC Womens Health. 2014;14:152-.

21. Anguzu G, Flynn A, Musaazi J, Kasirye R, Atuhaire LK, Kiragga AN, et al. Relationship between socioeconomic status and risk of sexually transmitted infections in Uganda: Multilevel analysis of a nationally representative survey. Int J STD AIDS. 2019;30(3):284-91.

22. Zou G. A modified poisson regression approach to prospective studies with binary data. American journal of epidemiology. 2004;159(7):702-6.

23. Richardson DB, Kinlaw AC, MacLehose RF, Cole SR. Standardized binomial models for risk or prevalence ratios and differences. Int J Epidemiol. 2015;44(5):1660-72.

24. Ferrer R, Klein WM. Risk perceptions and health behavior. Curr Opin Psychol. 2015;5:85-9.

25. ROYAK-SCHALER R, DEVELLIS BM, SORENSON JR, WILSON KR, LANNIN DR, EMERSON JA. Breast Cancer in African-American Families. 1995;768(1):281-5.

26. Spector D, Mishel M, Skinner CS, Deroo LA, Vanriper M, Sandler DP. Breast cancer risk perception and lifestyle behaviors among White and Black women with a family history of the disease. Cancer Nurs. 2009;32(4):299-308.

27. Gorin SS, Albert SM. The Meaning of Risk to First Degree Relatives of Women with Breast Cancer. Women Health. 2003;37(3):97-117.

28. Park K, Chang SJ, Kim HC, Park EC, Lee ES, Nam CM. Big gap between risk perception for breast cancer and risk factors: nationwide survey in Korea. Patient education and counseling. 2009;76(1):113-9.

29. Metcalfe KA, Quan M-L, Eisen A, Cil T, Sun P, Narod SA. The impact of having a sister diagnosed with breast cancer on cancer-related distress and breast cancer risk perception. 2013;119(9):1722-8.

30. Katapodi MC, Lee KA, Facione NC, Dodd MJ. Predictors of perceived breast cancer risk and the relation between perceived risk and breast cancer screening: a meta-analytic review. Prev Med. 2004;38(4):388-402.

31. Coleman MPP, Quaresma MM, Berrino FMD, Lutz J-MMD, De Angelis RB, Capocaccia RP, et al. Cancer survival in five continents: a worldwide population-based study (CONCORD). Lancet Oncology, The. 2008;9(8):730-56.

32. Elsie K-M, Gonzaga MA, Francis B, Michael KG, Rebecca N, Rosemary BK, et al. Current knowledge, attitudes and practices of women on breast cancer and mammography at Mulago Hospital. Pan Afr Med J. 2010;5:9-.

33. Gyawali B, Shimokata T, Honda K, Tsukuura H, Ando Y. Should low-income countries invest in breast cancer screening? Cancer causes \& control : CCC. 2016;27(11):1341-5. 